\title{
Possible Protective Effect of Ginger Extract and Beetroot Juice Against Cisplatin Induced Testicular and Cytogenetic Toxicity in Adult Male Albino Rats
}

Asmaa A. Elshiekh ${ }^{1}$, Hala R. Elkolaly ${ }^{1}$, Noura M. Tawfeek ${ }^{1}$, Amira A. Mohamed ${ }^{2}$ and Aml A. Mohamed ${ }^{1}$

${ }^{1}$ Department of Forensic Medicine and Clinical Toxicology, Faculty of Medicine for Girls, Al-Azhar University,

${ }^{2}$ Department of Genetic and Cell Biology, National Research Centre, Dokki, Egypt

*Corresponding author: Asmaa Abdo Elshiekh, E-Mail: drasmaa.abdo@yahoo.com, Mobile: 01288160100

\begin{abstract}
Background: cisplatin (Cis) is an efficient platinum-derived anticancer drug. It has been successfully used in clinical oncology against diverse types of cancers. Testicular toxicity of cisplatin is of great concern because of increasing number of longer survival of cancer patients treated with cisplatin.

Objective: the present study aimed to investigate the possible protective role of ginger extract and red beetroot juice against testicular and cytogenetic toxicity induced by cisplatin.

Materials and Methods: sixty adult male albino rats were divided randomly into 6 groups (10 rats each). All groups were received the treatment once daily for 5 weeks, 4 days per week. At the end of experimental period samples were collected and then the levels of malondialdehyde (MDA), reduced glutathione (GSH), catalase (CAT), and testosterone hormone were measured.

Results \& Conclusion: cisplatin treated animals recorded a significant increase in MDA level and a significant decrease in reduced glutathione (GSH) and catalase activities .Significant improvement occurred on co administration of GE or BRJ to cis treated animals. Significant decrease in serum concentration of testosterone in cis treated animals was recorded, which improved significantly by co administration of GE or BRJ. A significant reduction in sperm count and motility and a significant increase in sperm head and tail abnormalities were noticed in cis treated animals which improved significantly on co-administration of GE or BRJ. Histopathological lesions which were observed in cis treated animals improved on co-administration of GE or BRJ. Finally BRJ caused more improvement in all theses parameters when compared with GE.
\end{abstract}

Keywords: Cisplatin (Cis), cytogenetic, chromosomal aberrations, testes, ginger extract (GE), beetroot juice (BRJ).

\section{INTRODUCTION}

The modern life style and environmental pollution have been the causes of increased cancer burdens in the world. Chemotherapy is one of the most important methods used in cancer therapy ${ }^{(\mathbf{1})}$.

Cisplatin is one of the most potent chemotherapy drugs widely used for cancer treatment. The discovery of cisplatin, Cis-Diamine Dichloro Platinum (II) or CDDP), was a corner stone which triggered the interest in platinum (II) and other metal-containing compounds as potential anticancer drugs ${ }^{(2)}$.

It has been reported that cisplatin (Cis) show activity against a broad spectrum of many solid tumors, including cervical, ovarian, testicular, bladder and lung cancers as well as solid tumors resistant to other drug regimens ${ }^{(\mathbf{3})}$.

The main mechanism of cisplatin cytotoxic effect is believed to result from its interaction with DNA, through the formation of covalent adducts between certain DNA bases and the platinum compound leading to cytotoxic lesions in tumors and other rapidly dividing cells ${ }^{(4)}$.

The toxicity of Cis seems to be dose dependent due to the cumulative effect of the drug, where the accumulation of Cis produces obvious necrotic changes within the tissues of the affected organs. The generation of reactive oxygen species (ROS) and nitrogen species (NS) is one of the possible mechanisms responsible for Cis toxicity through their oxidative stress injury and suppression of the antioxidant defense system ${ }^{(5)}$.

Use of Cis in the treatment of tumors is restricted due to its toxic effects including nephrotoxicity, hepatotoxicity and cardiotoxicity ${ }^{(6)}$.

Toxic effect of cisplatin on different systems like cardiovascular system and reproductive system are of great concern because of increasing number of longer survival of cancer patients treated with cisplatin $^{(7)}$.

Cisplatin-based chemotherapy results in impaired spermatogenesis, chromosomal abnormalities in spermatozoa and temporary or permanent azoospermia. Pathogenesis of testicular damage after cisplatin exposure is generally attributed to oxidative damage ${ }^{(8)}$.

Animals administered Cis develop severe testicular damage characterized by germ cell apoptosis, Leydig cell dysfunction and testicular steroidogenic disorder leading to infertility. Spermatogenesis is affected by $\mathrm{CP}$ by inhibiting nucleic acid synthesis of germ cells. $\mathrm{CP}$ also inhibit testosterone production by damage of Leydig cells ${ }^{\left(\boldsymbol{( 9}^{\prime}\right.}$.

Antioxidants are found in every living cell and all biological species and scavenge reactive oxygen within cells. Therefore, biological antioxidants in human diet, within intracellular antioxidants, and enzyme system protect against the potentially harmful effects of excessive oxidative stress and prevent various pathologic diseases. 
Antioxidants also maintain structural and tissue integrity ${ }^{(\mathbf{1 0})}$.

Ginger possess medicinal properties, and has been used since antiquity to treat ailments like cold, headaches, nausea, stomach upset, digestive, gastrointestinal disturbances, rheumatic complaints, diarrhea, nausea, asthma and parasitic infections, arthritis and muscular discomfort in the various alternative and folk systems of medicine in the world (11).

Extracts of the ginger are rich in shagaols and gingerols which exhibit anti-inflammatory, antioxidant and anti-carcinogenic proprieties under "in vitro" and "in vivo" systems ${ }^{(\mathbf{(})}$.

Red beet (Beta vulgaris L.) roots are cultivated all over the world as a food source and are also helpful in development of natural red dye. The color of red beet root is due to red betacyanin and yellow betaxanthin pigments that are placed in betalain or betanins compounds group. These Beet pigments called betalains are found as natural dyes in various food products for example yougurt, processed meat, baked goods, ice cream and candies. Various in vitro studies have verified that betalains from red beetroots have potent antioxidant activity ${ }^{(\mathbf{1 2})}$.

Beetroot juice (BRJ) contains colorants that can be divided into two categories of betalains: the red betacyanins and the yellow betaxathines. Betalain is important for cardiovascular health. Betanin, which makes up $95 \%$ of the total betacyanins, is more stable in the beetroot extract than in pure chemical form ${ }^{(\mathbf{1 3})}$.

\section{AIM OF THE WORK}

The aim of the present study was to evaluate the possible protective role of Ginger extract (GE) and Beetroot juice (BRJ) against cisplatin induced testicular and cytogenetic toxicity of adult male albino rats.

\section{MATERIALS AND METHODS}

\section{Chemicals used:}

Cisplatin: in its commercial form obtained from pharmacy, Cairo, Egypt.

Ginger Extract (GE): Ginger extract was obtained from Arab Company for Pharmaceuticals and Medicinal Plants (MEPACO, Cairo, Egypt) in tablet form.

Beetroot juice (BRJ): 2o kilo gram where purchased from a local market, Cairo, Egypt. The juice was prepared from chopped roots and filtered through stainless steel refinery.

\section{Animal grouping and experimental design:}

The present study was carried out on 60 adult male albino rats, with average body weight ranging from 180-200 grams (gms). They were obtained from Helwan animal breeding farm, Cairo, Egypt. This study was conducted in accordance with ethical procedures and policies approved by Animal Care and Use Committee of Faculty of Medicine, AlAzhar University, Cairo, Egypt.

The handling of animals was following the rules for the Experimental Research Ethics approved by Research Ethics Committee at Faculty of Medicine for Girls Al-Azhar University.

The animals were divided randomly into 6 groups (10 rats each). All groups were receiving the treatment once daily for 5 weeks, 4 days per week.

- Group I: served as control, received $1 \mathrm{ml}$ saline $0.9 \% \mathrm{NaCl}$ daily orally for 5 weeks.

- Group II: received only GE (310 mg/kg/day) by oral gavage for 5 weeks.

- Group III: received BRJ $8 \mathrm{ml} / / \mathrm{kg} /$ day by oral gavage.

- Group IV: received cisplatin $(5 \mathrm{mg} / \mathrm{kg} / \mathrm{w}$, i.p.) for 5 weeks.

- Group V: received both cisplatin and G E as the same previous doses.

- Group VI: received both cisplatin and BRJ as the same previous doses.

\section{Specimens collection:}

- At the end of experimental period (5 weeks), the animals were fasted overnight and then anaesthetized with diethyl ether inhalation and blood samples were collected by direct puncture of retro- orbital venous plexus using glass capillaries in sterile separator. The blood samples were centrifuged at $2000 \mathrm{rpm}$ for $15 \mathrm{~min}$, to separate the sera then stored at $-20^{\circ} \mathrm{C}$ for assessment of biochemical parameters.

- After the collection of blood samples all animals sacrificed by cervical dislocation. One testis and both femora of each animal were dissected immediately for cytogenetic analysis and chromosomal aberrations studies and the other testis for histopathological examination.

Animals of all groups were exposed to biochemical, cytogenetic analysis and histopathological examination.

\section{1- Biochemical analysis:}

a- Quantitative estimation of MDA.

b- Quantitative estimation of reduced glutathione (GSH).

c- Quantitative estimation of CAT.

d- Quantitative estimation of serum level of testosterone.

2- Cytogenetic analysis:

a- Chromosomal preparation from bone marrow cells was prepared. 
b- Sperm count, motility and morphology: When the male rats were killed, both epididymis were also removed for sperm-morphology evaluation. The sperm smears were examined under light microscopy $(600 \mathrm{x})$, and morphological abnormalities were assessed following the criteria of Wyrobek et al. ${ }^{(14)}$.

\section{3-Histopathological examination:}

Testes sections were stained with the Hemtoxin \& Eosin stain.

\section{Statistical analysis:}

All values were expressed as mean \pm standard deviation (SD). All statistical analyses were performed using SPSS (version 20). Statistical differences among the experimental groups were assessed by ANOVA. Significant was defined at $\mathrm{p}<0.05$.

\section{RESULTS}

\section{I- Biochemical analysis}

a- MDA level as lipid peroxidation marker and antioxidant enzymes as reduced glutathione (GSH) and catalase (CAT): The data in Table (1) recorded that, animals treated with cisplatin showed significant increase $(\mathrm{P}<0.01)$ in serum MDA levels and decrease in (GSH) and CAT activity compared to control group. However, co-administration of GE or BRJ with cisplatin revealed significant improvement in these parameters. Also there was statistically significant decrease in MDA level and increase in catalase activity in BRJ treated group as compared to GE treated group.

b- Serum levels of testosterone: Table (2) revealed that, animals treated with cisplatin showed significant decrease in the serum level of testosterone hormone compared to control group. While co- administration of GE or BRJ caused significant improvement of testosterone level compared to CIS treated group. However, co-administration of BRJ with cisplatin revealed more improvement when compared with GE treated group.

\section{II- Cytogenetic analysis:}

a- Chromosomal aberrations in bone marrow cells: Table (3) revealed that, treatment with CIS resulted in a significant increase $(\mathrm{P}<0.01)$ in different types of numerical \& structural chromosomal aberrations in bone marrow cells in the form of gaps, break, centromeric attenuation and end mitosis in comparison to control group. While rats treated with GE or BRJ showed dramatically reduction in the frequency of chromosomal aberrations in bone marrow cells compared to CIS treated group. Also treatment with BRJ produced significantly more correction than GE treated group. b- Sperm count, motility and morphology:

1- Sperm morphology: Table (4) revealed that there was highly statistically significant difference between control group and CIS toxic group in changes in sperm morphology. Whereas the rats exposed to CIS showed statistically significant increase $(p<0.01)$ in sperm head abnormalities in the form of amorphous head and divided head. Also there was significant increase in sperm tail abnormalities in the form of coiled tail and divided tail compared to control group. However, concomitant administration of GE or BRJ with Cis resulted in a significant recovery $(p<0.01)$ from sperms head and tail abnormalities compared to Cis treated group. Also improvement in Sperm morphology was statistically significant in BRJ treated group when compared to GE treated group.

2- Sperm count and motility: Table (4) revealed a significant reduction $(\mathrm{P}<0.01)$ in sperm count in rats treated with Cis compared to control rats. However, concomitant administration of GE or BRJ with Cis resulted in a significant improvement of total sperm count compared to Cis treated group.

Regarding motility, it was observed that administration of GE or BRJ with Cis had improved percentage of motility compared to Cis treated group. Also improvement in Sperm motility was statistically significant in BRJ treated group when compared to GE treated group.

\section{III- Histopathological analysis:}

Haematoxylin and Eosin (H\&E): Light microscopic examination of the testes sections in control, GE and BRJ groups showed seminiferous tubules lined with spermatogenic cells which are; spermatogonia with dark small nuclei (green arrow) and primary spermatocytes (red arrow). The interstitial cell of lyedig (black arrow) can be seen (Fig. 1). On the other hand, light microscopic examination of the testes sections in cis treated rats showed disturbances in spermatogenesis process including apparent decrease in number of spermatogenic cells, appearance of many vacuoles (V) multiple acidophilic areas; areas of degenerated cells can be observed (Fig. 2).

Furthermore, the combined treatment of GE or BRJ with Cis revealed some improvements in spermatogenesis process as judged by the testes showed seminiferous tubules lined with spermatogenic cells which are; spermatogonia with dark small nuclei and primary spermatocytes, the sperms (S) can be noticed within the lumen of the tubule. Few small vacuoles (V) can be seen (Fig. 3). 
Table (1): The possible protective role of GE and BRJ on changes in MDA level as lipid peroxidation marker and antioxidant markers induced by cisplatin toxicity in adult male albino rats (mean value \pm SD)

\begin{tabular}{|c|c|c|c|c|}
\hline \multirow{2}{*}{\multicolumn{2}{|c|}{$\begin{array}{c}\text { Groups } \\
\mathrm{N}=10 \text { rats } / \text { group } \\
\end{array}$}} & MDA (g/dl) & Catalese activity(u/l) & GSH (mg/dl) \\
\hline & & Mean \pm SD & Mean \pm SD & Mean \pm SD \\
\hline \multicolumn{2}{|c|}{ Control } & $9.28 \pm 0.71$ & $793.22 \pm 14.21$ & $32.71 \pm 2.28$ \\
\hline \multicolumn{2}{|c|}{ GE } & $9.14 \pm 0.71 \mathrm{a}$ & $797.56 \pm 9.60 \mathrm{a}$ & $32.18 \pm 3.74 \mathrm{a}$ \\
\hline \multicolumn{2}{|c|}{ BRJ } & $8.86 \pm 0.71 \mathrm{a}$ & $804.66 \pm 8.08 \mathrm{a}$ & $33.10 \pm 2.24 \mathrm{a}$ \\
\hline \multicolumn{2}{|l|}{ Cis } & $22.17 \pm 1.88 \mathrm{a}^{*}$ & $294.74 \pm 9.86 \mathrm{a}^{*}$ & $10.66 \pm 1.56 \mathrm{a}^{*}$ \\
\hline \multicolumn{2}{|c|}{ Cis+GE } & $13.48 \pm 1.28 \mathrm{~b}^{*}$ & $700.04 \pm 7.24 \mathrm{~b}^{*}$ & $23.69 \pm 1.66 b^{*}$ \\
\hline \multicolumn{2}{|c|}{ Cis + BRJ } & $12.26 \pm 1.23 \mathrm{~b}^{*} \mathrm{c}^{*}$ & $717.45 \pm 11.51 b^{*} c^{*}$ & $24.25 \pm 1.57 \mathrm{~b}^{*} \mathrm{c}$ \\
\hline \multirow{2}{*}{$\begin{array}{l}\text { One way } \\
\text { ANOVA }\end{array}$} & F test & 134.214 & 1223.701 & 113.902 \\
\hline & $P$ value & $0.001 *$ & $0.001 *$ & $0.001 *$ \\
\hline
\end{tabular}

GE: ginger extract; B RJ: beet root juice, Cis :cisplatin; SD: standard deviation; a: [GE,BRJ, CIS compared to the control group; $\mathbf{b}=$ the treated groups compared to cis; * = significant $(\mathrm{P} \leq 0.05) ; * *=$ highly significant $(\mathrm{P} \leq 0.01)$, GSH reduced glutathione),CAT (catalase); $\mathbf{c}=\mathrm{CIS}+\mathrm{GE}$ groups compared to CIS+BRJ groups; ${ }^{*}=$ significant $(\mathrm{P} \leq 0.05) ; * *=$ highly significant $(\mathrm{P} \leq 0.01)$, GSH reduced glutathione), CAT (catalase).

Table (2): The possible protective role of GE and BRJ on changes in the testosterone level induced by cisplatin toxicity in adult male albino rats (mean value \pm SD)

\begin{tabular}{|c|c|c|}
\hline \multirow{2}{*}{\multicolumn{2}{|c|}{$\begin{array}{c}\text { Groups } \\
\mathrm{N}=10 \text { rats } / \text { group }\end{array}$}} & Testosterone (ng/ml) \\
\hline & & Mean \pm SD \\
\hline \multicolumn{2}{|l|}{ Control } & $14.24 \pm 1.57$ \\
\hline \multicolumn{2}{|l|}{ GE } & $13.91 \pm 1.57 \mathrm{a}$ \\
\hline \multicolumn{2}{|l|}{ BRJ } & $14.74 \pm 1.12 \mathrm{a}$ \\
\hline \multicolumn{2}{|l|}{ Cis } & $4.95 \pm 0.97 \mathrm{a}^{*}$ \\
\hline \multicolumn{2}{|l|}{ Cis+GE } & $9.57 \pm 0.97 b^{*}$ \\
\hline \multicolumn{2}{|l|}{ Cis+BRJ } & $10.82 \pm 1.13 b^{*} c^{*}$ \\
\hline \multirow[t]{2}{*}{ One way ANOVA } & F test & 69.654 \\
\hline & P value & $0.001 *$ \\
\hline
\end{tabular}

Table (3): The possible protective role of GE and BRJ on changes in the chromosome induced by cisplatin toxicity in adult male albino rats (mean value \pm SD)

\begin{tabular}{|c|c|c|c|c|c|c|c|c|}
\hline \multirow{2}{*}{\multicolumn{2}{|c|}{$\begin{array}{l}\text { Groups } \\
\text { N=10 rats / group }\end{array}$}} & Gap & Break & $\begin{array}{l}\text { Centromeric } \\
\text { Attenuation }\end{array}$ & Deletion & Fragmentation & End Mitosis & Numerical total \\
\hline & & Mean \pm SD & Mean \pm SD & Mean \pm SD & Mean \pm SD & Mean \pm SD & Mean \pm SD & Mean \pm SD \\
\hline \multicolumn{2}{|l|}{ Control } & $1.00 \pm 1.15$ & $0.40 \pm 0.52$ & $2.30 \pm 0.95$ & $0.00 \pm 0.00$ & $0.00 \pm 0.00$ & $0.00 \pm 0.00$ & $3.80 \pm 2.15$ \\
\hline \multicolumn{2}{|l|}{ GE } & $0.50 \pm 0.71^{\mathrm{a}}$ & $0.20 \pm 0.42 \mathrm{a}$ & $1.80 \pm 0.92 \mathrm{a}$ & $0.00 \pm 0.00 \mathrm{a}$ & $0.00 \pm 0.00 \mathrm{a}$ & $0.20 \pm 0.42 \mathrm{a}$ & $2.90 \pm 1.60 \mathrm{a}$ \\
\hline \multicolumn{2}{|l|}{ BRJ } & $0.40 \pm 0.70^{\mathrm{a}}$ & $0.20 \pm 0.42 \mathrm{a}$ & $1.00 \pm 1.05 \mathrm{a}^{*}$ & $0.00 \pm 0.00 \mathrm{a}$ & $0.00 \pm 0.00 \mathrm{a}$ & $0.00 \pm 0.00 \mathrm{a}$ & $2.29 \pm 0.76 \mathrm{a}$ \\
\hline \multicolumn{2}{|l|}{ CIS } & $3.40 \pm 0.97^{* * *}$ & $3.10 \pm 0.99^{a^{* *}}$ & $6.10 \pm 0.99^{\mathrm{a}^{* * *}}$ & $2.10 \pm 1.10^{a^{*}=}$ & $1.80 \pm 1.03^{\mathrm{a}^{* *}}$ & $3.90 \pm 0.744^{a^{* *}}$ & $26.40 \pm 2.55^{\mathrm{a} * *}$ \\
\hline \multicolumn{2}{|l|}{ CIS+GE } & $1.00 \pm 0.67^{b^{* *}}$ & $0.89 \pm 0.60^{\mathrm{b} *}$ & $2.50 \pm 1.18^{b^{* * *}}$ & $0.89 \pm 0.33^{b^{*}=}$ & $0.71 \pm 0.49^{b *}$ & $1.22 \pm 0.97^{b^{*}}$ & $7.50 \pm 2.80^{b^{* *}}$ \\
\hline \multicolumn{2}{|c|}{ CIS+BRJ } & $1.00 \pm 0.67^{b^{* *}}$ & $0.30 \pm 0.48^{b^{* *} c^{*}}$ & $2.10 \pm 0.57^{b^{* *}}$ & $0.30 \pm 0.48^{b^{* *} c}$ & $0.20 \pm 0.42^{b * * c^{*}}$ & $0.70 \pm 0.95^{b^{* *}}$ & $5.60 \pm 1.35^{b^{* *} c^{*}}$ \\
\hline \multirow{2}{*}{$\begin{array}{l}\text { One } \\
\text { way } \\
\text { ANOVA }\end{array}$} & F test & 13.675 & 23.559 & 24.642 & 21.475 & 16.340 & 38.621 & 168.180 \\
\hline & $P$ value & $0.001^{*}$ & $0.001^{*}$ & $0.001^{*}$ & $0.001^{*}$ & $0.001^{*}$ & $0.001^{*}$ & $0.001^{*}$ \\
\hline
\end{tabular}


Table (4): The possible protective role of GE and BRJ on changes in the sperm morphology, sperm count and motility induced by cisplatin toxicity in adult male albino rats (mean value \pm SD)

\begin{tabular}{|c|c|c|c|c|c|c|c|}
\hline \multirow{2}{*}{\multicolumn{2}{|c|}{$\begin{array}{c}\text { Groups } \\
\mathrm{N}=10 \text { rats } / \text { group }\end{array}$}} & Coiled Tail & Divided Tail & Amorphus Hea & Divided Head & $\begin{array}{c}\text { Sperm count } \\
\text { millions/gm } \\
\text { testes }\end{array}$ & Motility (\%) \\
\hline & & Mean \pm SD & Mean \pm SD & Mean \pm SD & Mean \pm SD & Mean \pm SD & Mean \pm SD \\
\hline \multicolumn{2}{|l|}{ Control } & $1.50 \pm 1.27$ & $1.30 \pm 0.95$ & $1.80 \pm 0.79$ & $0.70 \pm 0.48$ & $34.18 \pm 2.03$ & $71.86 \pm 1.33^{\mathrm{a}}$ \\
\hline \multicolumn{2}{|l|}{ GE } & $0.70 \pm 0.82^{\mathrm{a}}$ & $1.20 \pm 0.42^{\mathrm{a}}$ & $1.40 \pm 0.84^{\mathrm{a}}$ & $0.30 \pm 0.48^{a}$ & $34.06 \pm 1.74^{\mathrm{a}}$ & $65.33 \pm 18.46^{\mathrm{a}}$ \\
\hline \multicolumn{2}{|l|}{ BRJ } & $0.60 \pm 0.70^{a}$ & $0.20 \pm 0.42^{\mathrm{a}^{*}}$ & $0.60 \pm 0.70^{\mathrm{a}^{*}}$ & $0.20 \pm 0.42^{a}$ & $35.33 \pm 1.42^{\mathrm{a}^{*}}$ & $76.92 \pm 3.99^{a}$ \\
\hline \multicolumn{2}{|l|}{ Cis } & $12.00 \pm 2.00^{\mathrm{a}^{* * *}}$ & $12.50 \pm 2.17^{\mathrm{a}^{* *}}$ & $12.30 \pm 2.21^{\mathrm{a}^{* * *}}$ & $12.10 \pm 2.33^{\mathrm{a}^{* *}}$ & $19.53 \pm 1.80^{\mathrm{b}^{* * *}}$ & $30.59 \pm 2.97^{\mathrm{a}^{* *}}$ \\
\hline \multicolumn{2}{|l|}{ Cis+ GE } & $3.00 \pm 1.41^{\mathrm{b}^{* *}}$ & $2.90 \pm 0.74^{b^{* *}}$ & $3.70 \pm 1.16^{\mathrm{b}^{* *}}$ & $2.80 \pm 0.79^{b^{* *}}$ & $26.83 \pm 1.95^{b^{* *}}$ & $53.30 \pm 2.74^{b^{*}}$ \\
\hline \multicolumn{2}{|c|}{ Cis+ BRJ } & $1.60 \pm 0.97^{b^{* *} c^{*}}$ & $1.80 \pm 1.23^{\mathrm{b} * * \mathrm{c} *}$ & $2.70 \pm 0.67^{b^{* *} c}$ & $1.30 \pm 0.67^{b^{* *} c^{*}}$ & $29.00 \pm 1.95^{b^{* * *} c}$ & $59.81 \pm 2.48^{b^{* *} c^{*}}$ \\
\hline \multirow{2}{*}{$\begin{array}{l}\text { One } \\
\text { way } \\
\text { ANOVA }\end{array}$} & F test & 97.285 & 120.191 & 73.700 & 145.881 & 73.840 & 73.03 \\
\hline & $P$ value & $0.001^{*}$ & $0.001^{*}$ & $0.001^{*}$ & $0.001^{*}$ & $0.001^{*}$ & $0.001^{*}$ \\
\hline
\end{tabular}

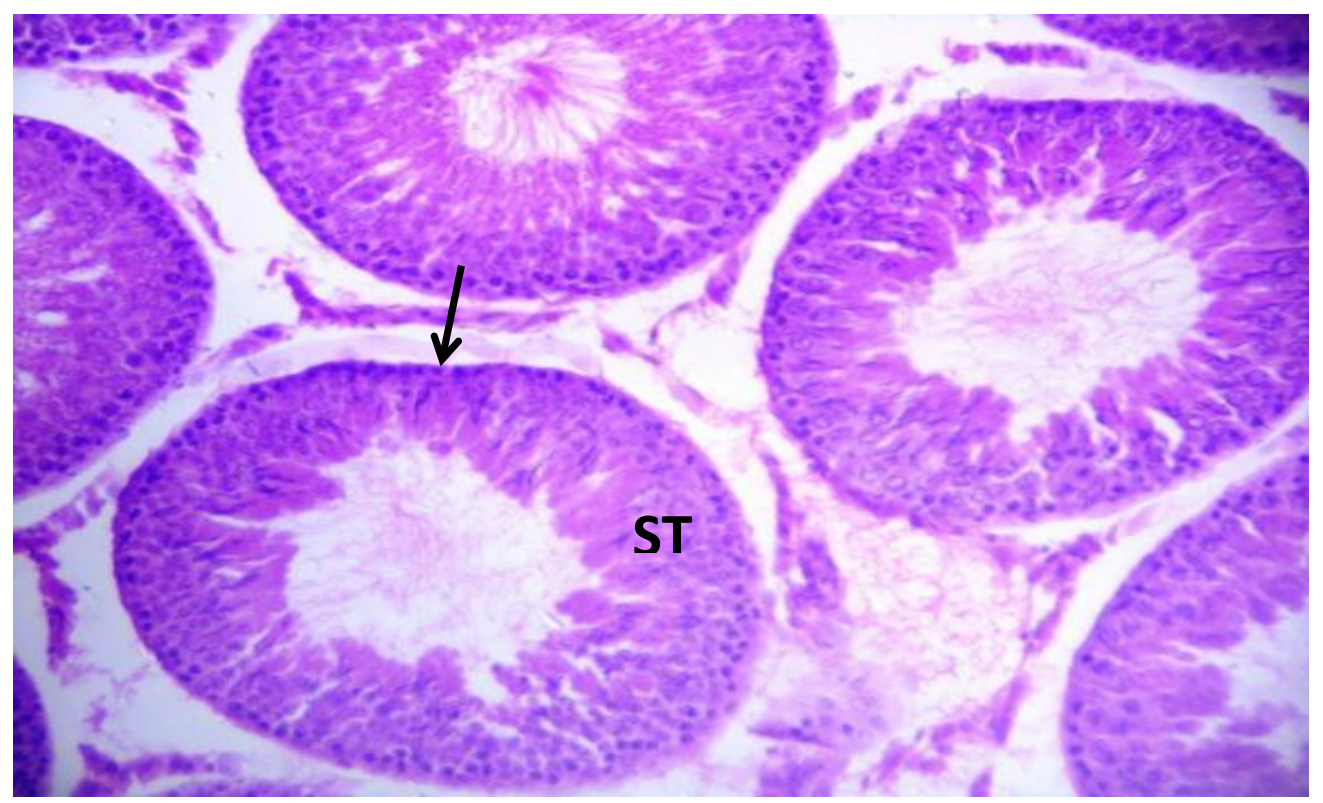

Fig. (1): A photomicrograph of a testis section of an adult albino rat control group, showing the seminiferous tubules (ST) and interstitial tissue in between (arrow) (H\&E X 200).

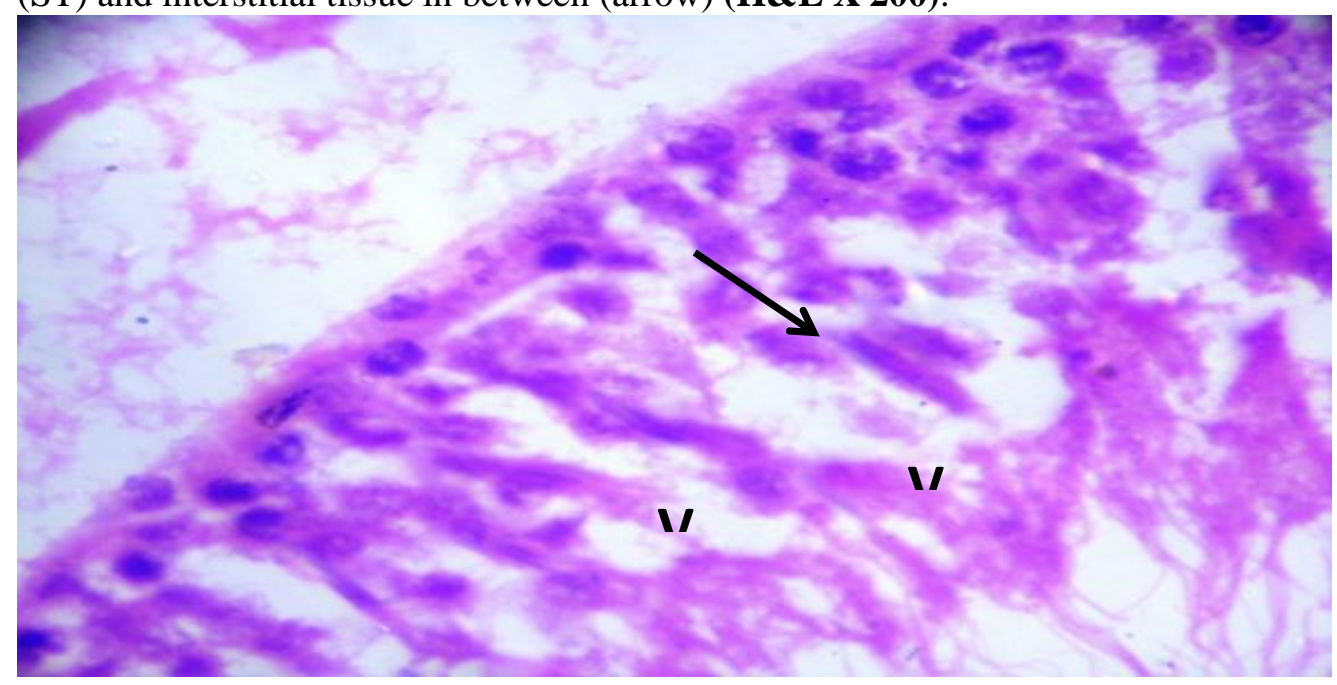

Fig. (2): A photomicrograph of a testis section of an adult albino rat cisplatin group, showing apparent decrease in number of spermatogenic cells. Many large vacuoles (V) can be seen within the seminiferous tubule. Multiple acidophilic areas; areas of degenerated cells (arrow) can be observed (H\&E X 400). 


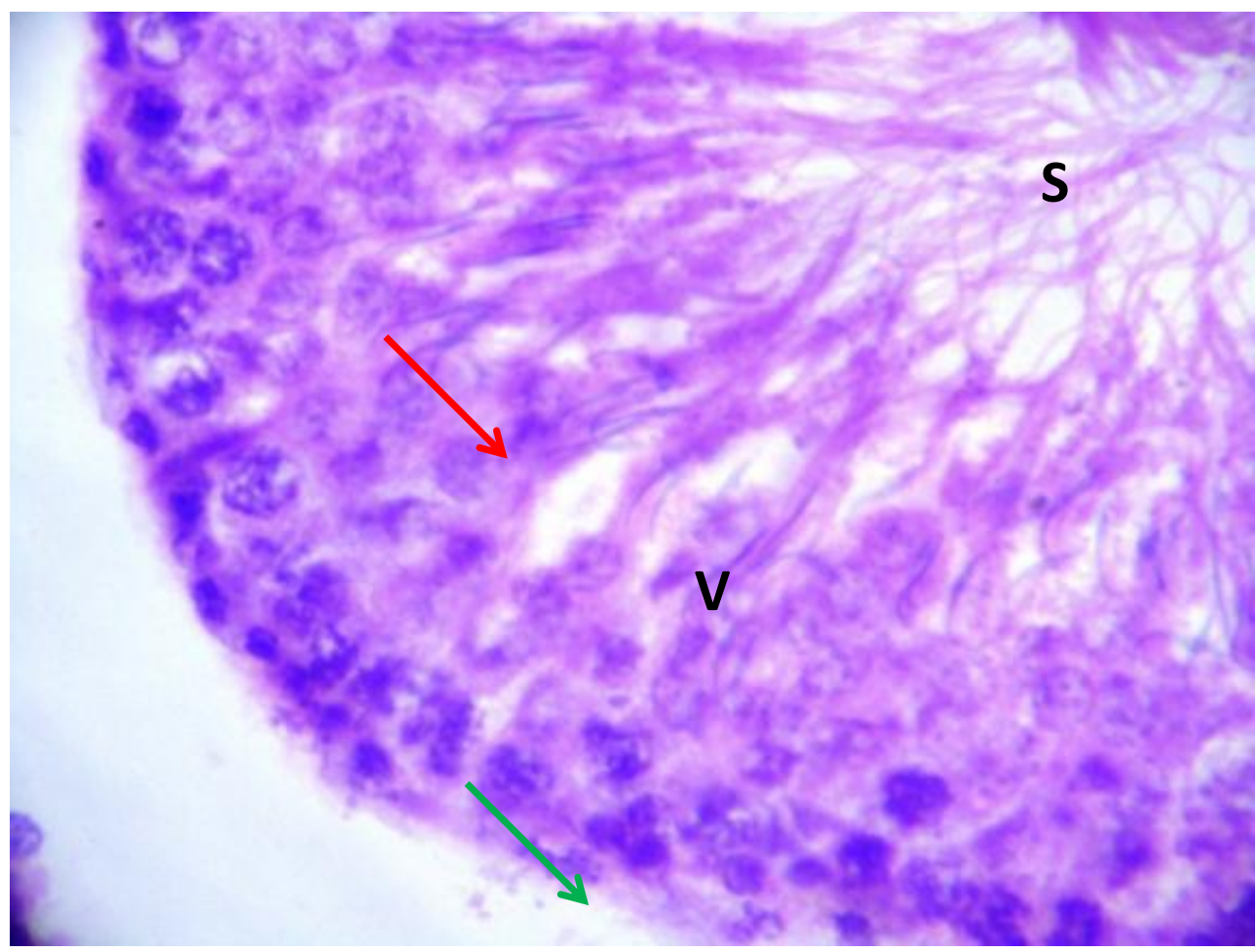

Fig. (3): A photomicrograph of a testis section of an adult albino rat cisplatin+BRJ group, showing the seminiferous tubules lined with spermatogenic cells which are; spermatogonia with dark small nuclei (green arrow) and primary spermatocytes (red arrow), the sperms (S) can be noticed within the lumen of the tubule. Few small vacuoles (V) can be seen (H\&E X 400).

\section{DISCUSSION}

Cisplatin, a chemotherapeutic agent, has been successfully used in clinical oncology against diverse types of cancer. It is an efficient platinum-derived alkylating agent that acts in unspecific phases of the cellular cycle against proliferating and resting cells. It interacts primarily with cytosine- and guanine-rich DNA regions and causes cellular damage ${ }^{(\mathbf{1 5})}$.

The mechanism of action of cisplatin toxicity is thought to be due to increased production of free oxygen radicals and decreased production of antioxidants. It has been claimed that organ damage related to free radicals occurs as a consequence of disrupted antioxidant defense mechanisms. Moreover, it was reported that the toxicity caused by cisplatin in the tissues was closely related to the increased lipid peroxidation ${ }^{(\mathbf{1 6})}$.

Despite its potent antineoplastic action, cisplatin's toxicity includes nephrotoxicity, hepatotoxicity, peripheral neuropathy, ototoxicity, azoospermia, sperm morphology and motility alterations. This drug affects spermatogenesis by inhibiting the nucleic acid synthesis of germ cells. In mammals, spermatogonia are sensitive to cisplatin and other different chemotherapeutic drugs. Moreover, cisplatin also seems to inhibit Leydig cell testosterone secretion and usual changes in hormonal levels observed during cisplatin treatment may be related to Leydig cell damage. Cisplatin also induces germ cell death in several different phases of spermatogenesis and has been associated with an increase in the frequency of programmed germ cell death ${ }^{(15)}$.

In the current study, administration of Cis to adult male albino rats for 5 weeks induced a state of oxidative stress represented by a significant elevation of malondialdehyde level in serum with a significant reduction of activity of serum antioxidant enzymes (reduced glutathione and catalase) activity. These results agreed with other studies which recorded a significant increase in MDA level and a significant decrease in reduced glutathione and CAT activities by Cis toxicity ${ }^{(17)}$.

It was concluded that, MDA is the end-product of lipid peroxidation. Lipid peroxidation is known to be the most harmful effect of free radicals in the cell. It was reported that cisplatin caused oxidative damage in the tissue increasing MDA concentration ${ }^{(16)}$.

The administration of GE and BRJ in the current study to Cis treated animals induced significant improvements in the lipid peroxidation marker and antioxidant enzymes. These results agreed with Balijepalli et al. ${ }^{(18)}$ and $\mathbf{A b a s}{ }^{(19)}$ who reported that, administration of ginger extract to CIS treated animals caused a significant improvement in the antioxidant parameters through overcoming the oxidative stress and up-regulating the endogenous antioxidant defense system. 
Gholampour et al. (20) found that oral administration of ginger extract significantly inversed ferrous sulfate-induced peroxidative damage in the liver as evidenced by lower levels of MDA which might be due to the antioxidative effect of ginger extract.

Váli et al. ${ }^{(21)}$ found that administration of BRJ showed a significant decline in serum MDA level in carbon tetrachloride toxic group.

Interestingly, flavonoid glycosides, derived from apigenin, present in beet stalks and leaves may have acted as natural exogenous antioxidants, reducing or minimizing the oxidative stress in mice ${ }^{\text {(22). }}$.

Antioxidants have been proven to be effective in ameliorating cisplatin-induced toxicity. Ginger extract is a potent antioxidant which is reported to have antitumor effect and to enhance the effect of many known anticancer agents in addition to reducing their toxicities as well ${ }^{(28)}$.

Váli et al. ${ }^{(21)}$ and Sadeek ${ }^{(23)}$ reported that oral administration of fresh red beetroot juice significantly result in increasement in catalase and SOD activity as compared to CCL4 group.

Beetroot is as an exceptionally rich source of antioxidant compounds. The betalain pigments in particular have been shown by several in vitro studies to protect cellular components from oxidative injury. Betanin's high antioxidant activity appeared to stem from its exceptional electron donating capacity and ability to defuse highly reactive radicals targeting cell membranes ${ }^{(24)}$.

Animals treated with CIS showed significant decrease in serum testosterone hormone level when compared to control group.

These results were in agreement with Turk $\boldsymbol{e t}$ al. ${ }^{(25)}$; Beytur et al. ${ }^{(26)}$ and Tousson et al. ${ }^{(27)}$ they reported a significant decrease in serum concentration of testosterone in toxicated rats with Cis.

This can be explained by severe damages in which cisplatin exerted on leydig and sertoli cells by increased generation of free radicals, also cisplatin administration in a relatively long term may resulted in suppression of upper axis (hypophysis-testis) and the reduction of testosterone and did not up regulate Luteinizing hormone $(\mathrm{LH})$ and follicular stimulating hormone (FSH ) release ${ }^{(28)}$.

Testosterone is a key hormone that regulates spermatogenesis and it is needed to initiate spermatogenesis at puberty and for the maintenance of this process in the adult. It also required for the compilation of meiosis and for the differentiation of the spermatids ${ }^{(29)}$.

The administration of GE or BRJ in the current study to Cis treated animals induced significant improvements in serum concentration of testosterone, which was in agreement with Arash et al. ${ }^{(30)}$ and Mohammadi et al. ${ }^{(31)}$ who reported that testosterone level increased in GE treated group when compared with Cyclophosphamide toxic group and this may be due to the antioxidative and androgenic activity of ginger, while improvement achieved by BRJ was due to its antioxidant activity.

Concerning to chromosomal aberrations in bone marrow cells observed in this study, data revealed genotoxic effect as there were highly significant increases in the frequency of numerical and structural aberrations. These results were confirmed by Kadel $\boldsymbol{e t}$ al. ${ }^{(7)}$ and Noshy et al. ${ }^{(32)}$ who found an increase in structural chromosomal aberrations in Cis toxic rats.

The frequency of chromosomal aberrations in bone marrow cells in animal group treated with GE, BRJ in the present study dramatically reduced compared to CIS toxic groups.

Concerning sperm count, motility and morphology illustrated in the current study a significant increase in sperm head and tail abnormalities and significant reduction in sperm count and motility were noticed in rats exposed to Cis compared to control group.

These results agreed with Amin and Hamza ${ }^{(9)}$; Amin et $\boldsymbol{a l l}^{\left({ }^{(33)}\right.}$ and Eid et al. $^{\left({ }^{(34)}\right.}$ whose studies have shown that cisplatin impaired rat testicular structure through inflicting oxidative stress and inducing cell apoptosis.

Turk et al. ${ }^{(25)}$ reported that spermatozoa are especially susceptible to peroxidative damage because of the high concentration of polyunsaturated fatty acids, which are involved in regulation of sperm maturation, spermatogenesis, capacitation, acrosome reaction and eventually in membrane fusion and low antioxidant capacity. Peroxidation of sperm lipids destroys the structure of the lipid matrix in the membranes of spermatozoa, it is associated with the rapid loss of intracellular ATP leading to axonemal damage, decreased sperm viability and increased mid-piece morphological defects, and even it completely inhibits spermatogenesis in extreme cases.

After treatment of CIS toxic group with either GE or BRJ there were statistically significant improvement of sperm count and motility. The results were in agreement with Arash et al. ${ }^{(30)}$ who found that ginger extract could cause a significant increase in Sertoli cells which might be one reason for the significant improvement of spermatogenesis by ginger extract.

Dillasamola et al. ${ }^{(35)}$ declared that beet root extract restore normal count and motility of sperms after toxic exposure to xenbiotic.

Beetroot supplementation might serve as a useful strategy to strengthen endogenous antioxidant defenses, helping to protect cellular components from 
oxidative damage, the powerful antioxidant, antiinflammatory and vascular-protective effects offered by beetroot and its constituents have been clearly declared to guard against toxicities from different xenobiotics ${ }^{(24)}$.

The histopathological lesions observed in the present results are in corroboration with the observed biochemical and cytogenetic changes. As there were decrease in the number of spermatogenic cells and degenerative changes in seminiferous tubule with vacuoles.

Regarding co administration with GE, BRJ to Cis toxic group in the current study, it was noted that it ameliorate these histopathological effects.

\section{CONCLUSION}

Considering the results obtained from the present study, it can be concluded that, rat intoxication with cisplatin induced state of oxidative stress which lead to disruption of reproductive cell functions in the form of disturbance in testosterone hormone level, chromosomal aberrations (structural \& numerical), and sperm count \&morphology abnormalities. Antioxidant activity of GE or BRJ partially reversed some of the cisplatin-related pathological effects on testes and cytogenic toxicity. Obviously co-administration of beet root juice with cisplatin caused more improvement in all these parameters when compared to ginner extract treated group.

\section{REFERENCES}

1. Al-Malki AL and Sayed A (2014): Thymoquinone attenuates cisplatin-induced hepatotoxicity via nuclear factor kappa- $\beta$. BMC Complementary and Alternative Medicine, (14):282-6.

2. Frezza M, Hindo S, Chen D et al. (2010): Novel metals and metal complexes as platforms for cancer therapy. Curr Pharm Des., (16): 1813-1825.

3. Kart A, Yilmaz C, Musa K et al. (2010): Caffeic acid phenethylester (CAPE) ameliorates cisplatin-induced hepatotoxicity in rabbit. Exp Toxicol Pathol., (62): 45-52.

4. Yang Z, Schumaker LM, Egorin MJ et al. (2006): Cisplatin preferentially binds mitochondrial DNA and voltage-dependent anion channel protein in the mitochondrial membrane of head and neck squamous cell carcinoma: possible role in apoptosis. Clin Cancer Res., (12):5817-5825.

5. Ashraf YN (2014): Protective effect of aged garlic extract against the oxidative stress induced by cisplatin on blood cells parameters and hepatic antioxidant enzymes in rats. Toxicology Reports, 1: 682-691.

6. Attyah AM and Ismail SH (2012): Protective Effect of Ginger Extract Against Cisplatin-Induced Hepatotoxicity and Cardiotoxicity in Rats. Iraqi J Pharm Sci., 1:27-33.

7. Kadel M, Jha CB, Sangraula H et al. (2013): Effects of cisplatin on testes and chromosome of rats: A histological and chromosomal study. J Pharmacovigilance, 1:4-9.
8. Salem EA, Salem NA, Maarouf AM et al. (2012): Selenium and lycopene attenuate cisplatin induced testicular toxicity associated with oxidative stress in wistar rats. Urology, (79):1184-88.

9. Amin A and Hamza A (2006): Effects of ginger and roselle on cisplatin induced reproductivetoxicity in rats. Asian J Androl., (5):607-612.

10.Tulunoglu O, Demirtas S, Tulunoglu I (2006): Total antioxidant levels of saliva in children. related to caries, age, and gender. Int J Paediatric Dent., 3:186-91.

11.Haniadka R, Saldanha E, Sunita V et al. (2013): A reviewof the gastroprotective effects of ginger (Zingiberofficinale Roscoe). Food Funct., 4: 845-855.

12. Nisa A, Saeed K, Hina $S$ et al. (2015): Nutritional, Antioxidant, Microbiological and Toxicological Studies on Red Dye Extracted from Red Beet Roots (Beta vulgaris). Research Journal of Chemical Sciences, 5(4): 16.

13.Lechner JF, Wang LS, Rocha CM et al. (2010). Drinking Water with Red Beetroot Food Color Antagonizes Esophageal Carcinogenesis in NNitrosomethylbenzylamine-Treated Rats. Journal of Medicinal Food, 13 (3): 733-739.

14. Wyrobek A, watchmarkrs G, Gorden L (1984): Sperm morphology testing in mice, in"Hand book of mutagenicity test procedures. Elsevier Science, Publishers BV, Second Edition, Pp. 739-50.

15.Lirdil C, Taiza SP, Estel S et al. (2008): Amifostine Protective Effect on Cisplatin-Treated Rat Testis. The Anatomical Record, 291:797-808

16. Durdu A, Mine G, Omer EY et al. (2013): The Effect of Mirtazapine on Cisplatin-Induced Oxidative Damage and Infertility in Rat Ovarie. Hindawi Publishing Corporation. http://dx.doi.org/10.1155/2013/327240

17. Abdurrauf Y, Ahmet A, Ali O Ç et al. (2007): Ellagic Acid Prevents Cisplatin-Induced Oxidative Stress in Liver and Heart Tissue of Rats. Basic \& Clinical Pharmacology \& Toxicology, 101(5):345-9.

18. Balijepalli MK, Tandra JN (2010): Influence of Different Cytokinins on the Growth, [6]-Gingerol Production and Antioxidant Activity of in vitro Multiple Shoot Culture of Ginger (Zingiber officinale Roscoe). J Ethnopharmacol., 127(2): 515-520.

19.Abas M (2017): Evaluation of the Protective Effects of Ginger Extract on Cisplatin Induced Cardiotoxicity in Male Albino Rats. Journal of Chemical and Pharmaceutical Research, 9(2):99-110.

20. Gholampour F, Behzadi GF, Owji SM et al. (2017): The protective effect of hydroalcoholic extract of Ginger (ZingiberofficinaleRosc.) against iron-induced functional and histological damages in rat liver and kidney. Avicenna J Phytomed., 7 (6): 542-553.

21. Váli L, Stefanovits-Bányai E, Szentmihályi K et al. (2007): Liver-protecting effects of table beet (Beta vulgaris var. rubra) during ischemia-reperfusion. Nutr., 23 (2):172-8

22.Lorizola MI, Cibele PBF, Mariana $P$ et al. (2018):Beet Stalks and Leaves (Beta vulgaris L.) ProtectAgainst HighFat Diet-Induced Oxidative Damagein the Liver in Mice nutrients. J. Ethnopharmacol., 10: 872-75. 
23. Sadeek EA (2011): Protective effect of fresh Juice from red beetroot (Beta vulgaris L.) and radish (Raphanussativus L.) against carbon tetrachloride induced hepatotoxicity in rat models. African J Biol Sci., 7(1): 69-84.

24. Tesoriere L, Fazzari M, Angileri F et al. (2008): In vitro digestion of betalainic foods. Stability and bioaccessibility of betaxanthins and betacyanins and antioxidative potential of food digesta. J Agric Food Chem., (56) 10487-10492.

25. Turk G, Atessahin A, Sçnmez M et al. (2008): Improvement of cisplatin-induced injuries to sperm quality, the oxidant-antioxidant system, and the histologic structure of the rat testis by ellagic acid. Fertil Steril., 89 (5): 1474-1481.

26. Beytur A, Ciftci O, Oguz F et al. (2012): Montelukast attenuates side effects of cisplatin including testiculars morphologica and hormonal damage in male rats. Cancer Chemother Pharmacol., 69 (1): 207-213.

27. Tousson E, Ezar H, Ahmed M et al. (2014): Abrogation by Curcumin on Testicular Toxicity Induced by Cisplatin in Rats. Journal of Cancer Research and Treatment, 2(3): 64-68.

28. Rezvanfar MA, Rezvanfar MA, Shahverdi AR et al. (2013): Protection of cisplatin-induced spermatotoxicity, DNA damage and chromatin abnormality by selenium nano-particles. Toxicol Appl Pharmacol., 266 (3): 356365.

29. Khattab HA, Inas ZA, Abdallaha IZ et al. (2010): Grape seed extract alleviate reproductive toxicity caused by aluminium chloride in male rats. Journal of American Science, 6 (12): 1200-9.

30. Arash KD, Fathiazad F, Nouri M et al. (2009): The effects of ginger on spermatogenesis and sperm parameters of rat. Iranian J Reprod Med., 7:7-12.

31. Mohammadi F, Nikzad $\mathrm{H}$, Taghizadeh $\mathrm{M}$ et al. (2013):Protective effect of Zingiberofficinale extract on rat testis after cyclophosphamide treatment. Blackwell Verlag GmbH Andrologia, 46: 680-686.

32. Noshy MM and Hamad HR (2013): Chlorophyllin Protects Against Cisplatin and 5-Fluorouracil Regimen Induced Genotoxicity and Cytotoxicity Without Affecting Their Antitumor Activity of Fenugreek (Trigonellafoenum-raecum) from two regions of Pakistan. Pakistan Journal of Food Science, 23: 144-147.

33. Amin A, Hamza AA, Kmbal A et al. (2008): Herbal extracts counteract cisplatin-mediated cell death in rat testis. Asian J Androl., (2):291-297.

34. Eid AH, Abdelkaderb NF, Abd El-Raoufa OM et al. (2016): protective effect of 1-carnitine against cisplatininduced testicular toxicity in rats. Az J Pharm Sci., 53: 1418.

35. Dillasamola D, Almahdy A (2016): The effect of ethanol extract of beetroot (L.) on the number, morphology spermatozoa and testis weigh in Male Mice (Mus Musculus) by exposure to heat. Research Journal of Pharmaceutical, Biological and Chemical Sciences, 7(1): 746-751. 